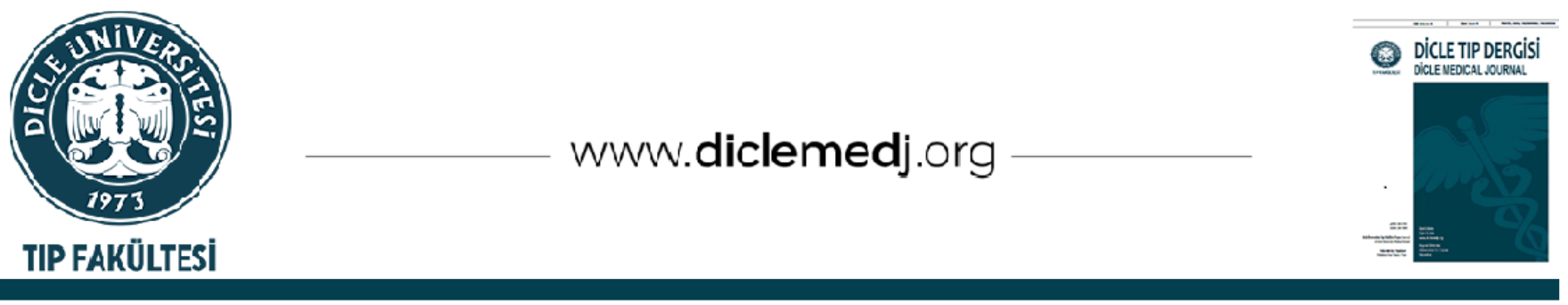

\title{
Obstetrik ve Jinekolojik Cerrahilerden Sonra Relaparotomi Yapılan Hastaların Değerlendirilmesi: Tersiyer Bir Merkezin 5 Yıllık Deneyimi
}

\author{
Reyhan Gündüz ${ }^{i}$, Elif Ağaçayak ${ }^{i}$, Senem Yaman Tunç ${ }^{D}$, Mulaim Sizer ${ }^{i}{ }_{1}$, Ahmet Yalınkaya ${ }_{1}$, \\ Talip Gül iD 1
}

1 Dicle Üniversitesi Tıp Fakültesi, Kadın Hastalıkları ve Doğum Anabilim Dalı, Diyarbakır, Türkiye

Geliş: 13.08.2021; Revizyon: 20.09.2021; Kabul Tarihi: 22.09.2021

\section{Öz}

Amaç: Kliniğimizde relaparotomi yapılan hastaların verilerini retrospektif olarak incelemek, relaparotomi insidansını, endikasyonlarını ve mortalite oranını belirtmektir.

Yöntemler: Çalışmamıza çalışma tarihleri arasında kliniğimizde relaparotomi yapılan 47 hasta dahil edildi. Hastaların demografik özellikleri, ilk operasyon endikasyonları ve ilk operasyon sırasında yapılan cerrahi işlem, ilk operasyonun hangi merkezde yapıldığı, relaparotomi endikasyonları ve relaparotomi sırasında yapılan cerrahi işlem, iki operasyon arasındaki süre, verilen kan transfüzyon ürünlerinin sayısı ve relaparotomi sonrası mortalite olup olmadığı not edildi. Kliniğimizin obstetrik ve jinekolojik relaparotomi insidansı ve relaparotomi sonrası mortalite oranı hesaplandı.

Bulgular: Çalışmamıza dahil edilen hastaların \%89,4'ü obstetrik relaparotomi, \%10,6'sı jinekolojik relaparotomi yapılan hastalardan oluşmaktadır. Kliniğimizin obstetrik relaparotomi insidansı \%0,1, jinekolojik relaparotomi insidansı \%0,06 olarak tespit edildi. Kliniğimizin relaparotomi sonrası mortalite oranını \%2,1 (1/47) olarak tespit ettik. Obstetrik relapatomi yapılan hastaların ilk operasyonlarının en sık \%81 (34) oranında sezaryen olduğu, endikasyon olarak en sık \%23,8 (10) geçirilmiş sezaryen olduğunu tespit ettik. Jinekolojik relaparotomi yapılan hastaların ilk operasyonlarının en sık \%80 (4) oranında total abdominal histerektomi olduğu, endikasyon olarak en sık \%60 (3) anormal uterin kanama olduğu tespit edildi. Relaparotomi yapılan hastaların hem obstetrik hem de jinekolojik relaparotomilerde en sık endikasyonunun hematom-hemoraji olduğunu belirledik (sırasıyla \%64,3 ve \%40 oranında). Relaparotomi operasyonunda yapılan ișlem olarak hem obstetrik hem de jinekolojik relaparotomilerde en sık olarak hematom boşaltımı- kanama kontrolü yapıldı̆̆ını tespit ettik (sırasıyla \%52.4 ve \%40 oranında).

Sonuç: Relaparotomi kararı gerekli hazırlıklar yapıldıktan sonra gecikmeden verilmelidir. Risk faktörü olan hastalar önceden bilgilendirilip ilk operasyonlarının mümkün olduğunca üçüncü basamak hastanelerde olmasını önermeliyiz. İlk operasyon sırasında gerekli kanama kontrolünü yaparak relaparotomi ihtiyacını azaltabileceğimizi düşünmekteyiz.

Anahtar kelimeler: Relaparotomi, obstetri, jinekoloji, hemoraji.

DOI: 10.5798/dicletip.1037785

Yazıșma Adresi / Correspondence: Reyhan Gündüz, Dicle Üniversitesi Tıp Fakültesi, Kadın Hastalıkları ve Doğum Anabilim Dalı, Diyarbakır, Türkiye email: ryhn.gunduz@gmail.com 


\title{
Evaluation of Patients Who Had Relaparotomy After Obstetric and Gynecological Surgery: 5 Years Experience of A Tertiary Center
}

\begin{abstract}
Objective: To retrospectively analyze the data of patients who underwent relaparotomy in our clinic, to indicate the incidence, indications and mortality rate of relaparotomy.

Methods: Our study included 47 patients who underwent relaparotomy in our clinic between the study dates. Demographic characteristics of the patients, indications for the first operation and the surgical procedure performed during the first operation, the center where the first operation was performed, the indications for relaparotomy and the surgical procedure performed during relaparotomy, the time between two operations, the number of blood transfusion products given, and the mortality after relaparotomy were noted. In our clinic, the incidence of obstetric and gynecological relaparotomy and the mortality rate after relaparotomy were calculated.

Results: Of the patients included in our study, 89.4\% consisted of patients who underwent obstetric relaparotomy, and $10.6 \%$ underwent gynecological relaparotomy. In our clinic, the incidence of obstetric relaparotomy was $0.1 \%$, and the incidence of gynecological relaparotomy was $0.06 \%$. We found the mortality rate of our clinic after relaparotomy to be $2.1 \%(1 / 47)$. We found that the first operations of patients who underwent obstetric relapatomy were cesarean section most frequently with a rate of 81\% (34) and a previous cesarean section was the most common indication in $23.8 \%$ (10). It was determined that total abdominal hysterectomy was performed most frequently in $80 \%$ (4) of the first operations of patients who underwent gynecological relaparotomy, and abnormal uterine bleeding was the most common indication in $60 \%$ (3). We determined that the most common indication for both obstetric and gynecological relaparotomy in patients who underwent relaparotomy was hematoma-hemorrhage $(64.3 \%$ and $40 \%$, respectively). We found that hematoma evacuation-bleeding control was the most common procedure performed in relaparotomy in both obstetric and gynecological relaparotomy (52.4\% and 40\%, respectively).
\end{abstract}

Conclusion: After the necessary preparations are made, the decision to relaparotomy should be made without delay. Patients with risk factors should be informed in advance and we should recommend that their first surgery be performed in tertiary hospitals as much as possible. We think that we can reduce the need for relaparotomy by controlling the bleeding during the first operation.

Keywords: Relaparotomy, obstetrics, gynecology, hemorrhage.

\section{GíRiş}

Relaparotomi terimi, ilk ameliyattan sonraki 60 gün içinde orijinal hastalık için gerçekleştirilen laparotomiyi ifade eder ${ }^{1}$. Relaparotominin amacı, önceki cerrahinin komplikasyonlarını yönetmek, bağırsak devamlılığını sağlamak, abdomenin fekal kontaminasyonunu önlemek, intestinal obstruksiyonu gidermek, hemostazı korumak, intra-abdominal enfeksiyon veya sepsisi önlemek ve gecikmiş küratif cerrahiyi gerçekleștirmektir. Ancak relaparotomi için uygun olmayan hasta seçimi, özellikle reoperasyondan açıkça fayda görmeyecek olanlar için zararlı olabilir. Böylelikle mortalite için risk faktörleri, yapılan ilk operasyondan farklı olabilir1. Relaparotomi için verilen karar zor bir karardır ve bu ameliyatların deneyimli cerrahi ekip tarafından yapılması gerekmektedir². Çünkü relaparotominin kendisi hem morbiditeyi hem de maternal mortalite riskini arttırır ${ }^{3}$.

Herhangi bir ameliyatın başarısı, ameliyattan sonra hastanın iyilik haline bağlıdır. Bu büyük ölçüde ameliyatın tekrarlanmamasına bağlıdır. Rapor edilen çeșitli çalışmalarda relaparotomi insidansı \%0.5-15 arasında değişmektedir ${ }^{4,5}$.

Acil ameliyatlar, kadın hastalıkları ve doğum bölümünde sık görülen bir durumdur. Majör acil operasyonların genellikle belirli risk ve komplikasyonları vardır. Bazı durumlarda konservatif yöntemlerle komplikasyonların yönetimi başarısız olur ve hastanın relaparotomi ihtiyacl gerekir6. Obstetri ve jinekoloji ile ilgili olarak literatürde daha çok sezaryen sonrası relaparotomi yapılan hastaların bildirildiğini tespit ettik. Ancak obstetri ve jinekoloji pratiğinde sezaryen dışında birçok cerrahi müdahalede relaparotomi ihtiyacı gerekebilir. 
Çalışmamızın amacl; obstetri ve jinekoloji kliniğimizde yapılan relaparotomi hastalarının verilerini değerlendirmek, relaparotomi insidansını ve mortalite oranını belirtmektir. $\mathrm{Bu}$ hastaların operasyon endikasyonlarını ve operasyon sırasında yapılan cerrahi işlemleri belirterek relaparotomi vakalarındaki maternal mortalite ve morbiditeyi azaltmaya yönelik önerilerde bulunmayı amaçladık.

\section{YÖNTEMLER}

Retrospektif çalışmamıza, Dicle Üniversitesi Tıp Fakültesi Kadın Hastalıkları ve Doğum Kliniği'nde ocak 2016 - ocak 2021 tarihleri arasında relaparotomi yapilan 47 hasta dahil edildi. Çalışma için Üniversite hastanemiz lokal etik kurulundan onay alındı (Etik kurul Tarih: 09.04.2021/No:221).

Çalışmamıza jinekoloji ve obstetri alanı ile ilgili ameliyat olup 60 gün içerisinde ilk ameliyatla ilişkili relaparotomi yapılan hastalar dahil edildi. İlk ameliyatını dış merkezde olup relaparotomi için kliniğimize sevk edilen ve ilk ameliyatı kendi kliniğimizde yapılan hastalar dahil edildi. Relaparotomi yapılan hastalar kendi kliniğimizde opere edilen hastalardan oluşmaktadır. Relaparotomi operasyonu dış merkezde yapılıp sonra takip için kliniğimize sevk edilen hastalar çalışmamıza dahil edilmedi. Obstetri ve jinekoloji kliniğimizde relaparotomi yapılan tüm hastalar çalışmaya dahil edilmiştir. İlk operasyondan sonra 60 gün içinde relaparotomi yapılan hastalar dahil edilmiștir. Hastaların demografik özellikleri, ilk operasyon endikasyonları ve ilk operasyon sirasinda yapılan cerrahi işlem, ilk operasyonun hangi merkezde yapıldığı, relaparotomi endikasyonları ve relaparotomi sırasında yapılan cerrahi işlem, iki operasyon arasındaki süre, verilen kan transfüzyon ürünlerinin sayısı ve relaparotomi sonrası mortalite olup olmadığı not edildi. Veriler hastane bilgi yönetim sistemi arşivi ve hasta dosyaları incelenerek elde edildi.
Kliniğimiz, eğitim ve araștırma kliniği olduğundan dolayı bütün operasyonlar biri öğretim üyesi diğeri araştırma görevlisi olmak üzere en az iki cerrah tarafından yapılmaktadır. Relaparotomiler ise bu konuda tecrübeli öğretim üyeleri tarafından yapılmaktadır. Kliniğimizde relaparotomi kararı hastanın klinik ve laboratuvar değerlerine bakılarak verilmektedir. Hastanın medikal tedavi veya konservatif tedavi ile stabilitesinin sağlanamadığı hematom, kanama, abse, fasya defekti gibi durumlarda relaparotomi kararı verilmektedir. Hastalara yoğun bakım yeri ayarlanıp kan hazırlığı yapıldıktan sonra hastalardan ayrıntılı onam alınıp relaparotomi yapılmaktadır.

İstatistiksel analiz için SPSS 21 istatistik paket programı kullanıldı. Veriler ortalama, standart sapma, sayı ve yüzde kullanılarak ifade edildi.

\section{BULGULAR}

Kliniğimizde çalışma tarihleri arasında 47 relaparotomi yapilan hasta tespit edildi. $\mathrm{Bu}$ hastaların \%89,4'ü (42) obstetrik relaparotomi, $\% 10,6$ 'sı (5) jinekolojik relaparotomi yapılan hastalardan oluşmaktadır. Obstetrik relaparotomi yapılan hastalardan ilk operasyonu kendi kliniğimizde olan hastaların oranı \%21,4 (9), jinekolojik relaparotomi yapılan hastalarda ilk operasyonu kendi kliniğimizde yapılan hastaların oranı \%80 (4) olarak tespit edildi. Diğer hastalar ilk operasyondan sonra diş merkezden kliniğimize sevk edilen hastalardır. Kliniğimizin relaparotomi insidansı \%0,1 (13/13308), bunların obstetrik relaparotomi insidansı \%0,1 (9/7936), jinekolojik relaparotomi insidansı \%0,06 (4/5872) olarak tespit edildi. Kliniğimizin relaparotomi sonrası mortalite oranını \%2,1 (1/47) olarak tespit ettik.

Obstetrik relaparotomi yapılan hastaların yaş ortalamaları 32.1 \pm 7.4 , jinekolojik relaparotomi yapılan hastaların yaş ortalamaları $48.0 \pm 11.5$ olarak tespit edildi. İki operasyon arasındaki süre obstetrik relaparotomi hastalarında $5,1 \pm 7,5$ gün, jinekolojik relaparotomi hastalarında $9 \pm 7,3$ gün olarak tespit edildi. Demografik ve klinik veriler Tablo 1 de belirtildi. 
Tablo I: Demografik ve klinik verilerin değerlendirilmesi

\begin{tabular}{|l|l|l|}
\hline & $\begin{array}{l}\text { Obstetrik } \\
\text { relaparotomi yapılan } \\
\text { hastaların verileri } \\
\mathrm{n}=42 \\
\text { Mean } \pm \text { SD (Min-Max) }\end{array}$ & $\begin{array}{l}\text { jinekolojik } \\
\text { relaparotomi } \\
\text { yapılan } \\
\text { hastaların verileri } \\
\mathrm{n}=5 \\
\text { Mean } \pm \text { SD (Min-Max) }\end{array}$ \\
\hline Yaş & $32.1 \pm 7.4(16-45)$ & $48.0 \pm 11.5(35-66)$ \\
\hline Gravida & $4.1 \pm 3.2(1-15)$ & $7.2 \pm 5.3(0-15)$ \\
\hline Parite & $3.4 \pm 2.2(0-10)$ & $6.8 \pm 4.9(0-14)$ \\
\hline Yaşayan & $3.3 \pm 2.0(0-9)$ & $5.8 \pm 4.0(0-11)$ \\
\hline Eritrosit replasmanı & $5.0 \pm 4.0(0-17)$ & $2.0 \pm 2.3(0-6)$ \\
\hline $\begin{array}{l}\text { Trombosit } \\
\text { replasmanı }\end{array}$ & $0.6 \pm 1.3(0-5)$ & $0.0 \pm 0.0(0-0)$ \\
\hline $\begin{array}{l}\text { Taze Donmuş Plazma } \\
\text { replasmanı }\end{array}$ & $3.7 \pm 3.3(0-12)$ & $1.0 \pm 2.2(0-5)$ \\
\hline $\begin{array}{l}\text { Fibrinojen } \\
\text { replasmanı }\end{array}$ & $0.4 \pm 0.8(0-3)$ & $0.0 \pm 0.0(0-0)$ \\
\hline $\begin{array}{l}\text { Iki } \\
\text { arasındaki süre (gün) }\end{array}$ & $5,1 \pm 7,5(0-30)$ & $9 \pm 7,3(1-17)$ \\
\hline
\end{tabular}

Veriler mean $\pm S D$ (min- max) olarak belirtildi
Obstetrik hastaların verilerini incelediğimizde; ilk operasyon olarak en sık \%81 (34) oranında sezaryen yapıldığını, endikasyon olarak en sık \%23,8 (10) geçirilmiş sezaryen, ikinci sılılıta plasenta previa totalis \%16,7 (7) olduğu tespit edildi. Relaparotomi operasyonunun \%64,3 (27) oranında hematom- hemoraji endikasyonuyla yapıldığını belirledik (Tablo 2). Jinekolojik hastaların verilerini incelediğimizde; ilk operasyon olarak en sik $\% 80$ (4) oranında total abdominal histerektomi yapıldığını, endikasyon olarak en sık \%60 (3) anormal uterin kanama olduğu tespit edildi. Relaparotomi operasyonunun \%40 (2) oraninda hematom- hemoraji endikasyonuyla yapıldığını belirledik (Tablo 3).

Tablo II: Obstetrik hastalara yapılan ilk operasyonları, ilk operasyon ve relaparotomi endikasyonları

\begin{tabular}{|c|c|c|}
\hline $\begin{array}{l}\text { İlk operasyon } \\
\text { Endikasyonu } \\
\text { n= } 42 \text { n (\%) }\end{array}$ & $\begin{array}{l}\text { Yapılan ilk } \\
\text { operasyon } \\
\text { n (\%) }\end{array}$ & $\begin{array}{l}\text { Relaparotomi } \\
\text { Endikasyonu } \\
\text { n (\%) }\end{array}$ \\
\hline Geçirilmiş sezaryen 10 (23.8) & Sezaryen 34 (81) & Hematom-hemoraji 27 (64.3) \\
\hline Plasenta previa totalis 7 (16.7) & $\begin{array}{lll}\text { Sezaryen+ } & \text { histerektomi } & 5 \\
(11.9) & & \end{array}$ & Abse 7 (16.7) \\
\hline İlerlemeyen eylem 6 (14.3) & $\begin{array}{l}\text { NVD sonrası } \\
\text { Laparotomi } 2 \text { (4.8) }\end{array}$ & Atoni 4 (9.5) \\
\hline $\begin{array}{l}\text { Plasenta invazyon } \\
\text { anomalisi } 5 \text { (11.9) }\end{array}$ & Rüptür onarımı 1(2.4) & $\begin{array}{l}\text { Plasenta invazyon } \\
\text { anomalisi } \\
\text { Sonrası kanama } 3 \text { (7.1) }\end{array}$ \\
\hline Atoni 4 (9.5) & & Fasya defekti 1 (2.4) \\
\hline HELLP 3 (7.1) & & \\
\hline Preeklampsi 3 (7.1) & & \\
\hline Uterin rüptür 2 (4.8) & & \\
\hline Plasenta dekolmanı 1 (2.4) & & \\
\hline Maternal kalp hastalığı 1 (2.4) & & \\
\hline
\end{tabular}


Tablo III: Jinekolojik hastalara yapılan ilk operasyonları, ilk operasyon ve relaparotomi endikasyonları

\begin{tabular}{|l|l|l|}
\hline $\begin{array}{l}\text { ilk operasyon } \\
\text { Endikasyonı } \\
\mathrm{n}=5 \mathrm{n}(\%)\end{array}$ & $\begin{array}{l}\text { Yapilan ilk } \\
\text { operasyon } \\
\mathrm{n}(\%)\end{array}$ & $\begin{array}{l}\text { Relaparotomi } \\
\text { Endikasyonu } \\
\mathrm{n}(\%)\end{array}$ \\
\hline Anormal Uterin Kanama 3 (60) & $\begin{array}{l}\text { Total } \\
\text { Abdominal } \\
\text { Histerektomi 4 (80) }\end{array}$ & Hematom- Hemoraji 2 (40) \\
\hline Adneksiyal Kitle 1 (20) & Abse boșaltımı 1 (20) & Abse 1 (20) \\
\hline Abse 1 (20) & & Cuff Kanaması 1 (20) \\
\hline & & Fasya Defekti 1 (20) \\
\hline
\end{tabular}

Obstetrik ve jinekolojik relaparotomi yapılan hastaların relaparotomi operasyonu sırasinda yapılan işlemlerini incelediğimizde; en sık olarak hematom boşaltımı- kanama kontrolü yapıldı̆̆ını tespit ettik (sırasıyla \%52,4 ve \%40 oranında). Obstetrik relaparotomi yapılan hastalarda ikinci sıklıkta \%28,5 (12) oranında total abdominal histerektomi yapıldığını belirledik (Tablo 4).

Tablo IV: Relaparotomi sırasında yapılan işlemler

\begin{tabular}{|l|l|l|}
\hline $\mathrm{n}=47$ & $\begin{array}{l}\text { Obstetrik } \\
\text { relaparotomi } \\
\mathrm{n}(\%)\end{array}$ & $\begin{array}{l}\text { Jinekoojik } \\
\text { relaparotomi } \\
\mathrm{n}(\%)\end{array}$ \\
\hline $\begin{array}{l}\text { Hematom Boşaltılması- } \\
\text { Kanama kontrolü }\end{array}$ & $22(52.4)$ & $2(40)$ \\
\hline Total Abdominal Histerektomi & $12(28.5)$ & - \\
\hline $\begin{array}{l}\text { Abse Boşaltımı } \\
\text { Abdominal Histerektomi }\end{array}$ & $5(11.9)$ & - \\
\hline $\begin{array}{l}\text { Abse Botal } \\
\text { Histerektomi }\end{array}$ & $1(2.4)$ & $1(20)$ \\
\hline Fasya Onarımı & $1(2.4)$ & - \\
\hline Cuff Onarımı & $1(2.4)$ & $1(20)$ \\
\hline \multicolumn{2}{|l|}{ Veriler yüzde (\%) olarak belirtildi } & $1(20)$ \\
\hline
\end{tabular}

\section{TARTIŞMA}

Hayat kurtarıcı bir operasyon olan relaparotomi, birçok laparotomi ameliyatında postoperatif dönemde gerekebilir. Relaparotomi ameliyatı hayat kurtarıcı bir operasyon olmasının yanında mortalitesi olan bir operasyondur. Relaparotomi; kararının verilmesi bakımından ve operasyon olarak zor bir cerrahi işlemdir. Bu nedenlerden dolayı, biz de çalışmamızda retrospektif olarak kliniğimizde yaplan relaparotomi olgularının verilerini inceledik ve sonuçlarımızla literatüre katkı sunmayı amaçladık.

Sridhar ve ark. ları obstetri ve jinekoloji alanında opere olup relaparotomi yapılan 36 hastanın verilerini incelemişlerdir. Relaparotomi insidansını \%0,76 olarak belirtmişlerdir. En slk relaparotomi endikasyonunu \%38,9 oranında intraperitoneal kanama ve relaparotomi sırasında yapılan işlem olarak hematom drenajı ve resutürasyon olarak belirtilmiştir. Çalışmalarında mortalite oranı \%5,6 olarak belirtilmiştir7. Shah ve ark. larının yaptıkları çalışmada genel cerrahi, obstetri ve jinekoloji alanında opere olup relaparotomi yapılan 146 hastanın verileri incelenmiştir. Bu hastalardan 102'si genel cerrahi, 44'ü obstetri ve jinekoloji alanında opere edilmiş. Relaparotomi oranı $\% 2,5$ olarak belirtilmiştir. Mortalite oranı \%23,2 olarak tespit edilmiştir8. Zia ve ark. ları yaptıkları çalışmada obstetrik ve jinekolojik relaparotomi yapılan 38 hasta dahil etmişlerdir. Bunların \%76,3'ü obstetri, \%23,7'si jinekoloji alanında opere edilen hastalardan oluşmaktadır. Relaparotomi insidansı \%0,43 olarak belirtilmiştir. Obstetrik relaparotomi insidansı \%0,55, jinekolojik relaparotomi insidansı \%0,24 olarak tespit edilmiştir. Relaparotomi için en sı endikasyonun intraabdominal kanama olduğu ve geçirilmiş multilp sezaryenin majör risk faktörü olduğu 
belirtilmiştir ${ }^{9}$. Sak ve ark. larının yaptıkları çalışmada obstetri ve jinekoloji alanında opere olup relaparotomi yapilan 113 hastanın verilerini incelemişlerdir. Mortalite oranını \%3,5 olarak belirtmişlerdir. İlk operasyonların \%69'unu sezaryen operasyonunun oluşturduğu belirtilmiştir. Relaparotomi endikasyonunu \%70,8 olarak kanama ve hematomun oluşturduğu belirtilmiştir ${ }^{3}$. Bizim çalışmamızda da relaparotomi yapılan hastaların \%89,4'ünü obsterik relaparotomi hastaları oluşturmaktadır. Relaparotomi insidansı \%0,1 ve mortalite oranını \%2,1 olarak tespit ettik. Literatürde yapılan çalışmalarda olduğu gibi bizim çalışmamızda da obstetrik relaparotomi yapılan hasta sayısını jinekolojik relaparotomi yapılan hasta sayısına göre daha fazla bulduk. Bunun sebebinin obstetrik vakaların acil olarak alınma oranının jinekolojik vakalara göre daha fazla olmasına bağlı olabileceğini düşünmekteyiz yani jinekolojik vakaların daha çok elektif şartlarda alınmasına bağlamaktayız. Relaparotomi oranlarına baktığımızda çalışmalarda farklı oranlarda olduğunu görmekteyiz. $\mathrm{Bu}$ oranın ilk operasyonun endikasyonuna, opere edildiği sağlık kurumuna, cerrahın tecrübesine ve ilk operasyonun acil mi elektif mi olduğuna göre değişebileceğini düşünmekteyiz. Relaparotomi endikasyonu bizim çalışmamızda literatürle uyumlu olarak hem obstetri hem de jinekoloji operasyonlarında en sık hematom- hemoraji olarak bulunmuştur. Aynı şekilde literatürle uyumlu olarak relaparotomi sırasında yapılan işlem hematom boşaltılması ve kanama kontrolü olarak tespit ettik. Bizim çalışmamızda da Zia ve ark. larının ${ }^{9}$ yaptıkları çalışmada belirttikleri gibi geçirilmiş sezaryen obstetrik relaparotomilerde majör risk faktörü olarak tespit edilmiştir. Çalışmamızda relaparotomi mortalite oranını yapılan çalışmalarla uyumlu bulduk. Ancak Shah ve ark. larının yaptıkları çalışmada mortalite oranını \%23 gibi yüksek bir oranda bulmuşlardır ${ }^{8}$. Bunun sebebini çalışmalarında obstetri ve jinekoloji vakalarının yanında genel cerrahi alanında opere edilen hastaları dahil etmelerine bağlı olduğunu düşünmekteyiz.

Alam ve ark. nın yaptıkları çalışmada obstetri ve jinekoloji alanında acil olarak opere edilip relaparotomi yapılan 15 hastanın verileri incelenmiş. $\mathrm{Bu}$ hastaların ikisinin ilk operasyonlarının kendi üçüncü basamak hastanelerinde yapıldığı diğer hastaların relaparotomi için sevk edildiği belirtilmiştir ${ }^{10}$. Bizim çalışmamızda da relaparotomi yapılan hastaların 34'ü $(\% 72,4)$ kliniğimize sevk edilen hastalardan oluşmaktadır. İlk operasyonu kendi kliniğimizde yapılıp relaparotomi olan hasta sayısını $13(\% 27,6)$ olarak tespit ettik. İlk operasyonlarını üçüncü basamak hastanede olan hastaların relaparotomi ihtiyacının az olmasını cerrahi ekibin tecrübesine ve sağlık kurumunun imkanlarının daha iyi olmasına bağlamaktayı.

Literatürde yapılan çalışmaların çoğunda obsterik ve jinekolojik relaparotomi yapılan hastaların birlikte değerlendirildiğini ve sonuçların birlikte verildiğini tespit ettik. Ancak Zia ve ark. larının yaptıkları çalışmada bizim çalışmamızda belirttiğimiz gibi jinekolojik relaparotomi yapılan hastaların verileri ayrı olarak belirtilmiştir ${ }^{9}$. Çalışmalarında 9 (\%23,7) jinekolojik relaparotomi yapılan hasta değerlendirilmiştir. $\mathrm{Bu}$ hastaların \%55,5'ine dilatasyon küretaj sonrası relaparotomi yapılmış ve bu hastalar dış merkezden sevk edilmişlerdir ${ }^{9}$. Bizim çalışmamızda jinekolojik relaparotomi yapılan hastalar çalışmamızın $\% 10,6$ 'sını (5) oluşturmaktadır ve bunlardan \%20'si (1) dış merkezden sevk edildi. Çalışmamızda jinekolojik relaparotomi yapılan hastaların \%80'nin ilk operasyonlarının kendi kliniğimizde yapılmış olmasını riskli jinekolojik operasyonların daha çok üçüncü basamak hastanemizde yapıldığına bağlamaktayız. Shyamal ve ark. larının yaptıkları çalışmada ilk cerrahileri kendi kliniklerinde yapılıp sonrasında ilk yedi gün içerisinde relaparotomi 
yapılan 47 hasta değerlendirilmiş. Jinekolojik relaparotomi insidansı obstetrik relaparotomilere göre daha fazla belirtilmesine rağmen mortalite oranı obstetrik relaparotomilerde daha fazla olarak belirtilmiștir ${ }^{11}$. Bizim çalıșmamızda ise jinekolojik relaparotomi insidansı obstetrik relaparotomilere göre daha az tespit edilmiştir. Ve jinekolojik relaparotomi olan hastalarda mortalite olmamıştır. Ancak jinekolojik relaparotomi yapılan hasta sayımızın az olmasindan dolayı bu konuda daha fazla hastanın dahil edildiği çalışmalara ihtiyaç olduğunu düşünmekteyiz.

Akkurt ve ark. larının yaptıkları çalışmada sezaryen sonrası kanama nedeniyle relaparotomi yapılan 46 hasta değerlendirilmiş. Geçirilmiş sezaryen sayısının artması, sezaryen süresinin uzun olması ve preeklampsi varlığının relaparotomi için bağımsız risk faktörü olduğu belirtilmiştir. Çalışmalarında maternal mortalite olmadığı belirtilmiștiri ${ }^{12}$. Sezaryen sonrası relaparotomi yapılan 64 hastanın dahil edildiği çalışmada plasenta previa ve doğumun ikinci evresinde acil sezaryen yapılan hastaların sezaryen sonrası relaparotomi için risk faktörü olduğu belirtilmiștir ${ }^{13}$. Yapılan başka bir çalışmada sezaryen sonrası relaparotomi yapılan 18 hasta değerlendirilmiş. \%16,7 oranında maternal mortalite bildirilmiştir. İki hastanın kardiyak arreste birinin de dissemine intravasküler koagülasyona bağlı olduğu belirtilmiştir ${ }^{14}$. Bizim çalışmamızda obstetrik relaparotomi yapılan hastaların \%81'ine sezaryen sonrası relaparotomi yapıldı. Sezaryen endikasyonu olarak literatürde yapılan çalışmalarla uyumlu olarak en sı \%23,8 oranında geçirilmiş sezaryen, ikinci sıklıkta ise $\% 16,7$ oranında plasenta previa totalise bağlı yapıldığını tespit ettik. Çalışmamızda total olarak maternal mortalitesi olan bir hastamız mevcuttu. $\mathrm{Bu}$ hastamızın mortalitesinin sezaryen sonrası relaparotomi yapıldıktan sonra gerçekleştiğini tespit ettik.
Demirci ve ark. larının yaptıkları çalışmada sezaryen veya vajinal doğumdan sonra ilk 24 saat içinde histerektomi yapılan 39 hastanın verileri incelenmiştir. 13 hastanın relaparotomi ihtiyacı olduğu belirtilmiştir. Bunların 3'ünün sezaryen sırasında yapılan histerektomi sonrası, 10 hastanın da sezaryen tamamlandıktan sonra olduğu belirtilmiştir ${ }^{15}$. Bizim çalışmamızda da obstetrik relaparotomi yapılan 42 hastanın \%11,9'na sezaryen histerektomi sonrası relaparotomi yapıldığını tespit ettik. Bu hastaların \%80'nine hematom hemoraji endikasyonuyla relaparotomi yapıldığını tespit ettik.

Çalışmamızın üstünlüğü üçüncü basamak hastanemizde hem obstetrik hem de jinekolojik relaparotomi yapılan hastaları çalışmaya dahil etmemiz ve bu hastaların verilerini obstetri ve jinekoloji olarak ayrı ayrı değerlendirmemizdir. Çalışmamızın limitasyonu ilk operasyonların acil ya da elektif olup olmadığı, ilk operasyonun süresi ve relaparotomi endikasyonu olarak belirttiğimiz hemorajinin yeri ile ilgili bilgilere ulaşamamış olmamı ve jinekolojik relaparotomi yapılan hasta sayısının az olmasıdır.

\section{SONUÇ}

Relaparotomi kararı gerekli hazırlıklar yapıldıktan sonra gecikmeden verilmelidir. Risk faktörü olan hastalar önceden bilgilendirilip ilk operasyonlarının mümkün olduğunca üçüncü basamak hastanelerde olmasını önermeliyiz. İlk operasyon sırasında gerekli kanama kontrolünü yaparak relaparotomi ihtimalini azaltabileceğimizi düşünmekteyiz.

Etik Kurul Kararı: Bu çalışma için Dicle Üniversitesi Tip Fakültesi Etik Kurulundan 09.04.2021/221 tarih ve sayı ile etik kurul onayı alındi.

Çıkar Çatışması Beyanı: Yazarlar çıkar çatışması olmadığını bildirmişlerdir.

Finansal Destek: Bu çalışma herhangi bir fon tarafından desteklenmemiştir. 
Declaration of Conflicting Interests: The authors declare that they have no conflict of interest.

Financial Disclosure: No financial support was received.

\section{KAYNAKLAR}

1. Unalp HR, Kamer E, Kar H. Urgent abdominal reexplorations. World J Emerg Surg. 2006; 1: 10. Available from http://www.wjes.org/content/1/1/10.

2. Unalp H, Kamer E, Onal M. Analysis of early relaparotomy after lower gastrointestinal system surgery. Surg Today. 2008; 38: 323-28.

3. Sak ME, Turgut A, Evsen MS, et al. Relaparotomy after initial surgery in obstetric and gynecologic operations: analysis of 113 cases. Ginekol Pol. 2012; 83: 429-32.

4. Hasan KC, Abdul Aemmah AK. A 5 year study of re laparotomies, planned and unplanned, in Al Hillah Teaching General Hospital. Med J Babylon. 2018; 15: 25-7.

5. Haluk RU, Erdinc K, Haldun $\mathrm{K}$, et al. Urgent abdominal re-explorations. World J Emerg Surg. 2006; 1: 10. doi:10.1186/1749-7922-1-10.

6. Rouf S, Sharmin S, Dewan F, et al. Relaparotomy after Cesarean Section : Experience from a Tertiary Referral and Teaching Hospital of Bangladesh . Bangladesh J Obstet Gynaecol. 2009; 24: 3-9.

7. Sridhar M, Susmitha C. Incidence and causes of relaparotomy after an obstetric and gynaecological operation. Int Surg J. 2016; 3: 301-4.
8. Shah P, Choksi D, Arun R, et al. Evaluation of relaparotomy in surgery and obstetrics and gynecology patients in tertiary care hospital in India: reason, morbidity, mortality: a case controlled study. Int Surg J. 2020; 7: 3707-12.

9. Zia S, Rafique M, Qureshi MA, et al. Analysis of Early Relaparotomy In Obstetric\& Gynaecological Surgeries. Annals. 2015; 21: 247-52.

10. Alam IP, Mahabuba, Das SR. Relaparotomy in Obstetrics and Gynaecology Department of Faridpur Medical College Hospital - Experience in One Year. Faridpur Med Coll J. 2012; 7: 75-8.

11. Shyamal D, Partha Pratim S, Aradhana K, et al. Early re-operations after gynecological and obstetrical surgery -a five years. J Obstet Gynecol India. 2010; 60: 507-10.

12. Akkurt MO, Coşkun B, Güçlü T, et al. Risk factors for relaparotomy after cesarean delivery and related maternal near-miss event due to bleeding. J Matern Fetal Neonatal Med. 2020; 33: 1695-9.

13. Weissmann Brenner A, Barzilay E, Meyer R, et al. Relaparotomy post cesarean delivery: characteristics and risk factors. Arch Gynecol Obstet. 2021. https://doi.org/10.1007/s00404-02106060-4.

14. Ragab A, Mousbah Y, Barakat R, et al. Relaparotomy after caesarean deliveries: Risk factors and how to avoid? J Obstet Gynaecol. 2015; 35: 1-3.

15. Demirci O, Tugrul AS, Yılmaz E, et al. Emergency peripartum hysterectomy in a tertiary obstetric center: nine years evaluation. J Obstet Gynaecol Res. 2011; 37: 1054-60. 